1. Doutor em Engenharia de Recursos naturais da Amazônia (UFPA). Pro-

fessor da Universidade da Amazônia (UNAMA).

E-mail: valeriovinagre@gmail.com

2. Mestre em arquitetura. Professora na UNAMA.

E-mail: menamata@gmail.com

3. Doutor em engenharia elétrica (UFPA). Professor do instituto Federal do Pará (IFPA).

E-mail: andrecavnas@gmail.com

4. Engenheiro Elétrico. Doutor em sistemas de energia elétrica (UFPA).

E-mail: blasques@ifpa.edu.br

5. Mestre em Engenharia de Produção pela Universidade Federal de Santa

Catarina.

E-mail: francisrober@terra.com.br

\title{
DOI: 10.5752/P.2316-1752.2016v23n33p58
}




\title{
ENERGIA SOLAR FOTOVOLTAICA EM EDIFÍCIOS HISTÓRICOS EM BELÉM DO PARÁ
}

\author{
PHOTOVOLTAIC SOLAR ENERGY IN HISTORIC BUILDINGS IN BELÉM \\ DO PARÁ
}
LA ENERGÍA SOLAR FOTOVOLTAICA EN EDIFICIOS HISTÓRICOS EN BELÉM DO PARÁ

\author{
Marco valério A. Vinagre ${ }^{1}$ \\ Filomena Mata Vianna Longo ${ }^{2}$ \\ André Cavalcante do Nascimento ${ }^{3}$ \\ Luís Carlos Macedo Blasques ${ }^{4}$ \\ Francisco R.R. França ${ }^{5}$
}

\begin{abstract}
Resumo de cobertura.

Abstract

This paper presents a methodology with architectural and engineering technical guidelines for integrating solar photovoltaic (PV) in historic buildings located in the State of Pará, in northern Brazil. The proposed methodology aims to evaluate the impact of PV integration in historic buildings in terms of architecture and energy performance in order to minimize the commitment of the cultural characteristics of the historical and protected buildings and maximizing the generation of PV electricity.
\end{abstract}

Este trabalho apresenta uma metodologia com orientações técnicas arquitetônicas e de engenharia para a integração da energia solar fotovoltaica (PV) em edifícios históricos localizados no Estado do Pará, na região norte do Brasil. A metodologia proposta tem como objetivo avaliar o impacto da integração PV em edifícios históricos, em termos de arquitetura e desempenho energético, a fim de minimizar o empenho das características culturais dos edifícios históricos e protegidos e maximizar a geração de eletricidade PV.

Palavras-chave: Edifício Integrado fotovoltaicos (BIPV). Arquitetura Solar. Edifícios históricos. Sistemas

Keywords: Building Integrated Photovoltaic (BIPV). Solar Architecture. Historic buildings. Roofing systems.

\begin{abstract}
Resumen
Este trabajo presenta una metodología con las directrices técnicas de arquitectura e ingeniería para la integración de la energía solar fotovoltaica (PV) en edificios históricos ubicados en el Estado de Pará, en el norte de Brasil. La metodología propuesta tiene como objetivo evaluar el impacto de la integración fotovoltaica en edificios históricos en términos de arquitectura y rendimiento de energía con el fin de minimizar el compromiso de las características culturales de los edificios históricos y protegidos y maximizar la generación de electricidad fotovoltaica.
\end{abstract}

Palabras clave: Fotovoltaicos integrados en edificios (BIPV). Arquitectura Solar. Edificios históricos. Sistemas de techado.

\section{Introdução}

A preocupação com a economia e a conservação de energia têm influenciado o campo de intervenção na proteção de prédios históricos. Essa preocupação ocorre devido ao constante crescimento que intensificou o incentivo e o uso de energias renováveis para a preservação e conservação nas áreas urbanas onde estão inseridos. Outro importante fator é o uso para o qual esses prédios antigos estão destinados, pois o mesmo é um dos requisitos básicos para a sua preservação.

Em particular, com as mudanças de uso ou com a necessidade de aumentar o nível de conforto, alternativas energéticas são necessárias nos prédios históricos, protegidos ou não por leis públicas. Caso essas alternativas afetem o sistema construtivo e/ou a aparência do prédio, a medida deve 
apresentar conceitos de reversibilidade. A experiência demonstra, entretanto, que qualquer tipo de intervenção provoca impactos no edifício, portanto, diferentes especialistas devem trabalhar juntos no planejamento e desenvolvimento de outras estratégias passivas para atingir um melhor desempenho tanto dos painéis quanto do conforto ambiental interno [1].

Nesse contexto, os arquitetos, principalmente os restauradores, são encorajados a pensar sobre o problema do consumo de eletricidade e como inserir, nessa categoria de edifício, as novas tecnologias de produção de eletricidade, com base em fontes renováveis, como a energia solar fotovoltaica (PV). Os resultados apresentados por várias pesquisas desenvolvidas na última década mostram que é um grande desafio, especialmente para os restauradores e projetistas, a integração ou adaptação de módulos fotovoltaicos em edifícios históricos protegidos [2].

O bioma Amazônia abrange uma área total de quase 6,3 miIhões de $\mathrm{km}^{2}$, atingindo nove diferentes países da América do Sul. 4,1 milhões de $\mathrm{km}^{2}$, a maior parte da área total da Amazônia, encontra-se em território brasileiro, alcançando nove estados [3]. Dois desses estados, Amazonas e Pará, contém a maior parte da riqueza natural desse bioma, incluindo o potencial solar que atinge anualmente a Amazônia [4].

No Brasil, os custos de eletricidade estão constantemente aumentando, esse é outro problema que os projetistas têm de enfrentar. A integração de um sistema fotovoltaico em um edifício histórico, se feito para minimizar o impacto arquitetônico e maximizar o desempenho energético, pode ser uma opção interessante para adicionar valor para o edifício e para reduzir seus custos operacionais.

\section{Potencial solar na região amazônica}

Considerando-se o Estado do Pará, mais especificamente a sua principal cidade, Belém, onde o presente estudo foi desenvolvido, diferentes fontes consideram a cidade como aquela que detém o melhor potencial de energia solar das principais cidades da região amazônica brasileira.

A aplicação SUNDATA [5], uma ferramenta nacional, indica um total de radiação anual de $1.847 \mathrm{kWh} / \mathrm{m}^{2}$ numa superfície idealmente orientada e inclinada, com azimute $(\gamma)$ de $180^{\circ}$ (orientada ao norte) e inclinação $(\beta)$ de $3^{\circ}$, resultando em uma média diária de 5,06 kWh / m².

O software METEONORM [6], um banco mundial de dados meteorológicos amplamente utilizado por especialistas de PV, indica valores semelhantes, com radiação anual total de 1.851 $\mathrm{kWh} / \mathrm{m}^{2}$ e média diária de 5,07 kWh / $\mathrm{m}^{2}$, considerando $\gamma=$ $180^{\circ}$ (orientada ao norte) e $\beta=6^{\circ}$-valores ideais consideradas pelo software.

Ressaltam-se duas características particulares do clima da cidade de Belém que afetam a instalação e o desempenho do sistema PV. A primeira é a baixa variabilidade mensal de incidência solar. O melhor mês considerado pelo Meteonorm, 
agosto, com a mesma orientação e ângulos de inclinação acima mencionados, apresenta uma média diária de 6,19 kWh / $\mathrm{m}^{2}$, apenas $18 \%$ mais elevada do que a média diária anual e $34 \%$ mais elevada do que a média diária do pior mês, fevereiro, $\operatorname{com~4,07~kWh~/~m².~}$

Outra característica, comum a todas as cidades de baixa latitude, é a indicação de baixos ângulos de inclinação para a instalação de módulos fotovoltaicos, como pode ser visto a partir dos ângulos $\beta$ indicados para instalações ideais $\left(3^{\circ}\right.$ pelo SUNDATA e $6^{\circ}$ pelo Meteonorm). As Instalações de fachada, portanto, apresentam uma considerável perda de desempenho do sistema. Por outro lado, mesmo a orientação norte sendo apontada como o ideal, a latitude muito baixa (1.456 Sul) de Belém indica que uma superfície orientada para sul apresenta uma perda quase insignificante de desempenho em comparação com superfícies orientadas para o norte. Para ilustrar essa característica, muito importante para a metodologia proposta neste trabalho, a Figura 1 apresenta o desempenho do sistema em comparação com uma instalação ideal (100\% para $\gamma=180^{\circ}$ e $\beta=6{ }^{\circ}$ ).

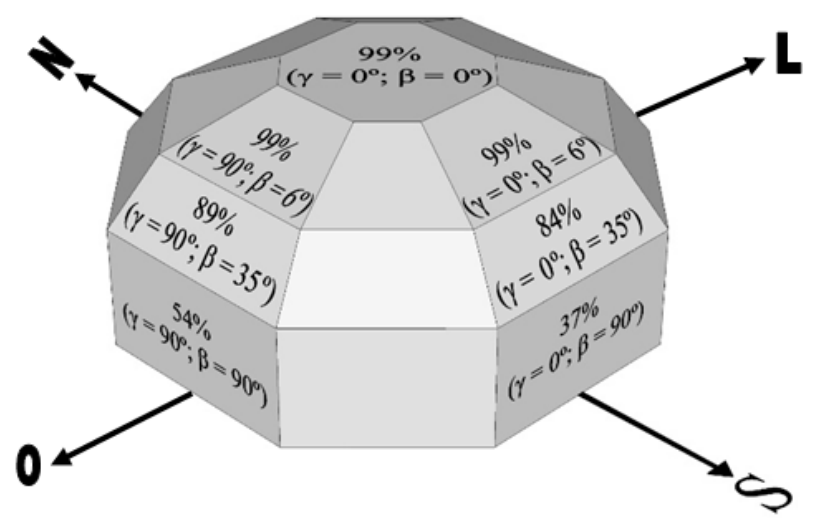

\section{Considerações sobre edifícios históricos e protegidos}

O edifício histórico protegido surge como um resultado da dinâmica da vida e do esforço coletivo, como elemento fundamental para preservar a memória que caracteriza a sociedade e, de certa forma, traz referências do passado para o presente. $O$ entendimento de que todos os edifícios históricos protegidos devem ser preservados em sua totalidade é um ponto de vista romântico, da mesma forma que não reconhecer o valor de sua preservação é um pensamento inadequado. A dinâmica da vida muda continuamente os edifícios, as cidades e o ambiente, e às vezes o "velho" tem de ser substituído pelo "novo". Atualmente, essas mudanças, sobretudo nas grandes cidades, ocorrem em um ritmo nunca antes visto [7].

A grande dinâmica dessas mudanças impõe aos edifícios históricos e aos monumentos impactos de alta proporção. No entanto, esses edifícios não têm de estar parados no tempo, caso contrário, eles seriam preservados apenas como um va-
Figura 1 - O desempenho do sistema PV para a cidade de Belém, de acordo com diferentes ângulos de orientação e inclinação.

Fonte: Autores, 2014. 
Ior cultural, e não como uma mercadoria, o que ajuda a garantir a sua existência [8].

Com o objetivo de atender a esses dois aspectos, o valor cultural e da mercadoria, a metodologia proposta neste trabalho demonstra que os sistemas fotovoltaicos são possíveis de instalar em edifícios e monumentos históricos, considerando o aspecto visual e as suas características construtivas, sem violar as leis de restauro, de preservação e regulamentos. O principal objetivo de qualquer trabalho de restauração de edifícios históricos é a conservação das características construtivas do monumento, bem como a manutenção de sua aparência [1].

\section{Edifícios históricos na Amazônia brasileira}

A manutenção do patrimônio cultural da região norte do Brasil, derivada da colonização Portuguesa, é uma importante ação social que atualmente está se transformando em uma ação econômica pelo efeito multiplicador que ele oferece, especialmente para o setor do turismo. Nas últimas três décadas, os edifícios históricos protegidos pelas leis públicas de Belém, capital do estado do Pará, localizada na região Norte do Brasil, passaram por intervenções para se tornarem centros de referência e atração para moradores e turistas.

A origem da cidade de Belém remonta ao ano de 1616 e sua configuração urbana começou com a formação de duas bases originais representadas pelos bairros chamados "Cidade Velha" e "Campina". Essas duas regiões, como se mostra na Figura 2, constituem o sítio histórico da cidade, onde há concentração expressiva de patrimônio arquitetônico, urbanístico e paisagístico. Essa área é protegida por leis públicas e sua malha urbana é composta por 146 quarteirões, com lotes pequenos e edifícios históricos construídos no alinhamento do lote sem folgas laterais, ruas estreitas e topografia regular [9].

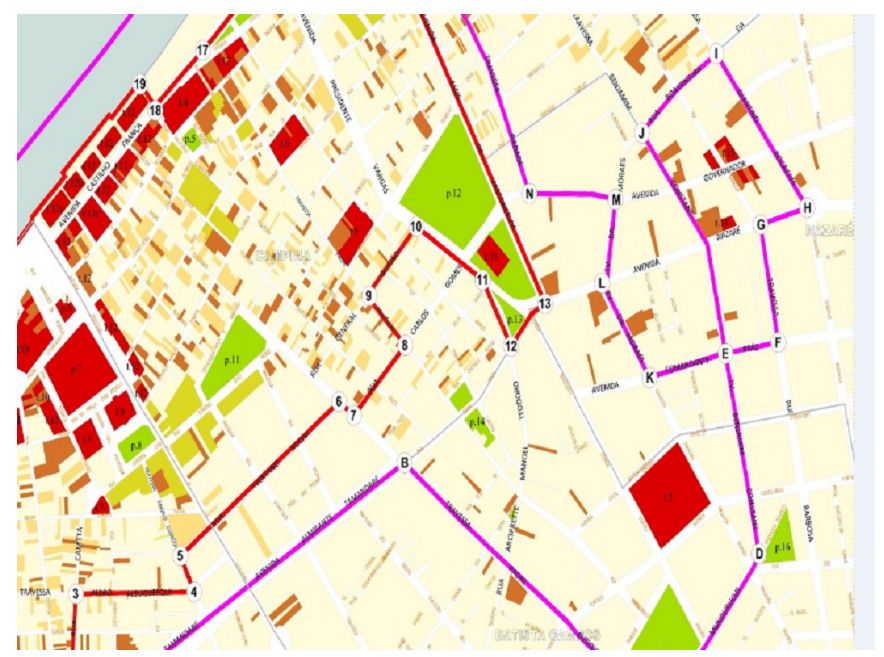

A arquitetura varia com predominância de casas térreas e sobrados e a presença constante de cemitérios em frente aos edifícios religiosos e palácios. Os edifícios inseridos em lotes estreitos
Figura 2 - Mapa do centro histórico de Belém.

Fonte: IPHAN(2011) [10].

Cadernos de Arquitetura e Urbanismo, v.23, n.33, 20 sem. 2016 


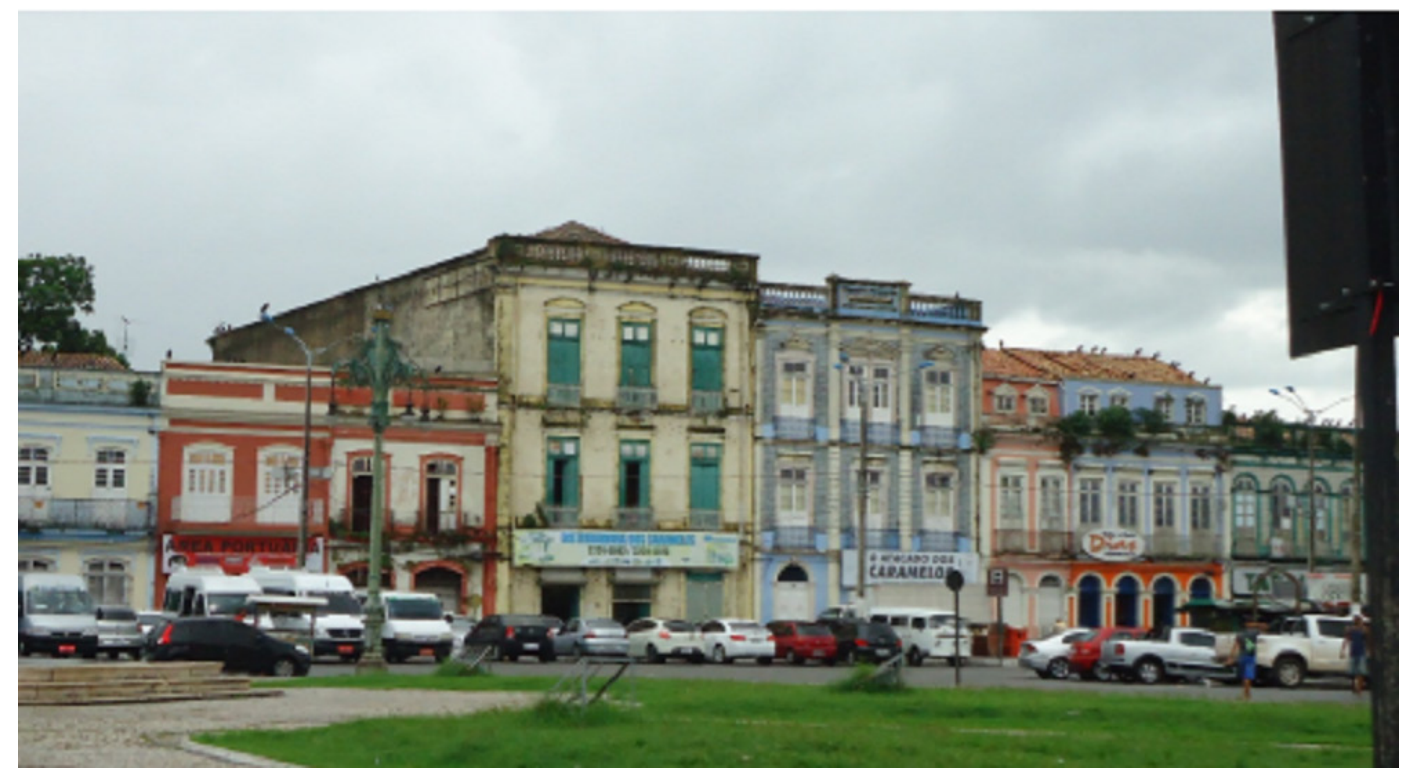

\section{Metodologia proposta}

O procedimento metodológico proposto visa atingir todos os tipos de edifícios históricos, protegidos ou não por leis públicas e, inicialmente, é aplicado em edifícios da região norte do Brasil, especialmente na cidade de Belém. No entanto, é importante mencionar que os resultados do método poderão ser utilizados para ajustar a sua aplicação em edifícios históricos de qualquer outra região do mundo. A metodologia é dividida em quatro etapas, a seguir apresentadas:

\section{Características gerais}

O primeiro passo tem como objetivo pesquisar e analisar dados referentes às características arquitetônicas do edifício histórico e do espaço urbano em que ele se insere. Esta pesquisa identifica a localização exata do edifício, a tipologia das ruas que o cercam, a sua orientação geográfica, sua escala de proteção, as suas características arquitetônicas, o material de construção, a área de plano da construção do telhado e sua inclinação. A Figura 4 apresenta um exemplo desta pesquisa para um edifício histórico de Belém.
Figura $3 \bullet$ Edifícios históricos na região de Belém.

Fonte: Autores, 2016 


\section{REGISTRO DASCARACTERÍSTICAS}

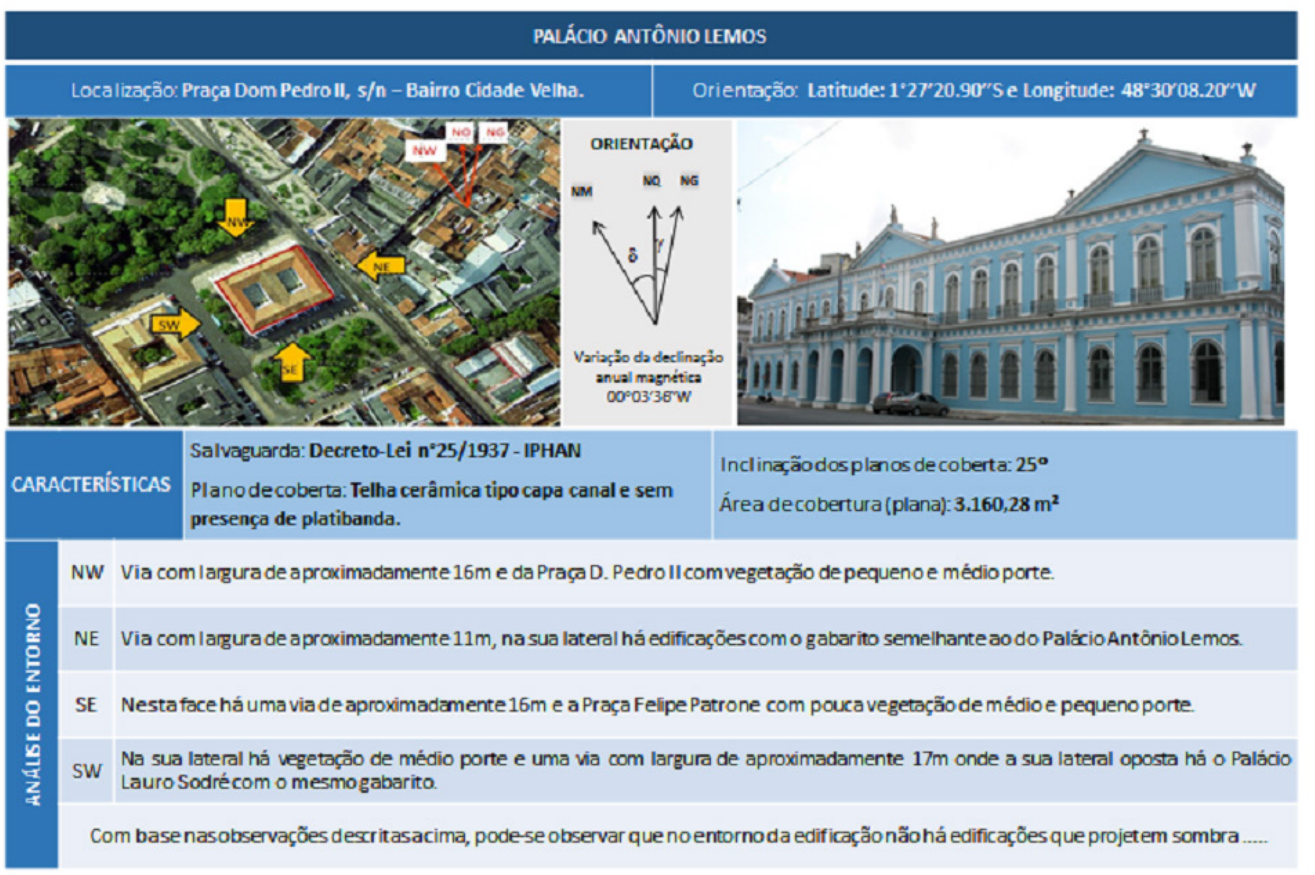

\section{Impacto visual}

O segundo passo analisa o impacto visual da eventual integração dos módulos fotovoltaicos em edifícios históricos. A metodologia desta etapa trabalha com três fatores condicionantes que estão relacionados com a imagem do edifício histórico e são importantes para a instalação dos sistemas fotovoltaicos. Esses três fatores são a visibilidade, a identidade e a estrutura visual [11].

O fator de visibilidade está associado especialmente à qualidade visual do edifício, ou seja, à capacidade do observador externo de reconhecer e organizar de forma coerente a envoltória do edifício (fachadas, telhados, janelas e outros). O fator imageabilidade, figurativamente chamado como visibilidade, concentra-se nas qualidades físicas do edifício, relacionando-as com os atributos da identidade e da estrutura da imagem. Por definição, imageabilidade é característica da edificação que possibilita aos indivíduos de uma sociedade evocar uma forte imagem do edifício.

Esses fatores acima explicados serão analisados pela metodologia através de várias vistas exteriores ao edifício, necessárias para investigar o nível de impacto visual que a possível integração PV pode causar sobre a legibilidade e a imageabilidade do edifício. A identidade é o fator que relaciona o significado individual ou particular do edifício histórico e sua relação estrutural ou espacial com a cidade. É o significado do edifício histórico, ou seja, a sua relação com a cidade, seja prático, tecnológico, emocional ou outra forma, diferente da relação
Figura 4 - Dados de identificação e classificação do edifício sob investigação e os seus arredores urbanos.

Fonte: Autores, 2014

Cadernos de Arquitetura e Urbanismo, v.23, n.33, $2^{0}$ sem. 2016 
estrutural. Esse significado não é facilmente influenciado por manipulação física. Esse requisito é representado na metodologia pelo nível de conservação do edifício e é estudada no primeiro passo do método - as características gerais.

Com base nessa informação inicial, a identificação e a análise dos dados dessa etapa estão relacionadas com a avaliação de visibilidade do plano de coberturas no espaço urbano. Essa etapa da metodologia tem como objetivo identificar o impacto visual da instalação de módulos fotovoltaicos em cada face do telhado do edifício histórico, classificado como: (1) impacto visual alto, quando a face do telhado é vista por qualquer observador no espaço urbano; (2) o impacto visual moderado, quando a face do telhado é vista por observadores dentro da área do edifício; e (3) impacto visual baixo, quando a face do telhado não pode ser vista por observadores a pé, apenas em vistas aéreas.

Esse é o primeiro fator de análise, chamado F1, e tem as seguintes pontuações: 0,50 ponto por impactos visuais altos; 0,75 ponto para impactos visuais moderados; e 1,00 ponto para impactos visuais baixos. O estudo de caso hipotético apresentado na subseção 4.5 explica a influência dessa pontuação no resultado da análise.

É importante mencionar que, especificamente, para a cidade de Belém não é considerada a integração em fachada de módulos fotovoltaicos, uma vez que os autores concluem que esse tipo de integração acaba deteriorando consideravelmente a imagem do edifício, com base no perfil dos edifícios históricos estudados (Palácio Antônio Lemos e São José Liberto). Isso explica o fato de que a metodologia considera apenas a área de coberturas dos edifícios para a instalação de módulos fotovoltaicos.

A pesquisa de dados para essa etapa é baseada em diferentes pontos de vista do edifício. Para analisar cada ponto de vista, alguns fatores importantes são considerados, tais como a topografia da área urbana, onde é inserido o edifício, uma vez que esse fator influencia a relação entre a imagem do edifício e o que os observadores assimilam diante os planos de rua e possíveis rotas do observador para chegar ao edifício em estudo. O produto desse passo, chamado fator F1, é então definido pela análise de uma planilha que contém todas as informações apresentadas acima. A Figura 5 mostra uma dessas planilhas para um edifício histórico de Belém. 


\section{ANÁUSE DO IMPACTO VISUAL DAINTEGRAÇÃODE FV NAS ÁREAS DE COBERTA}

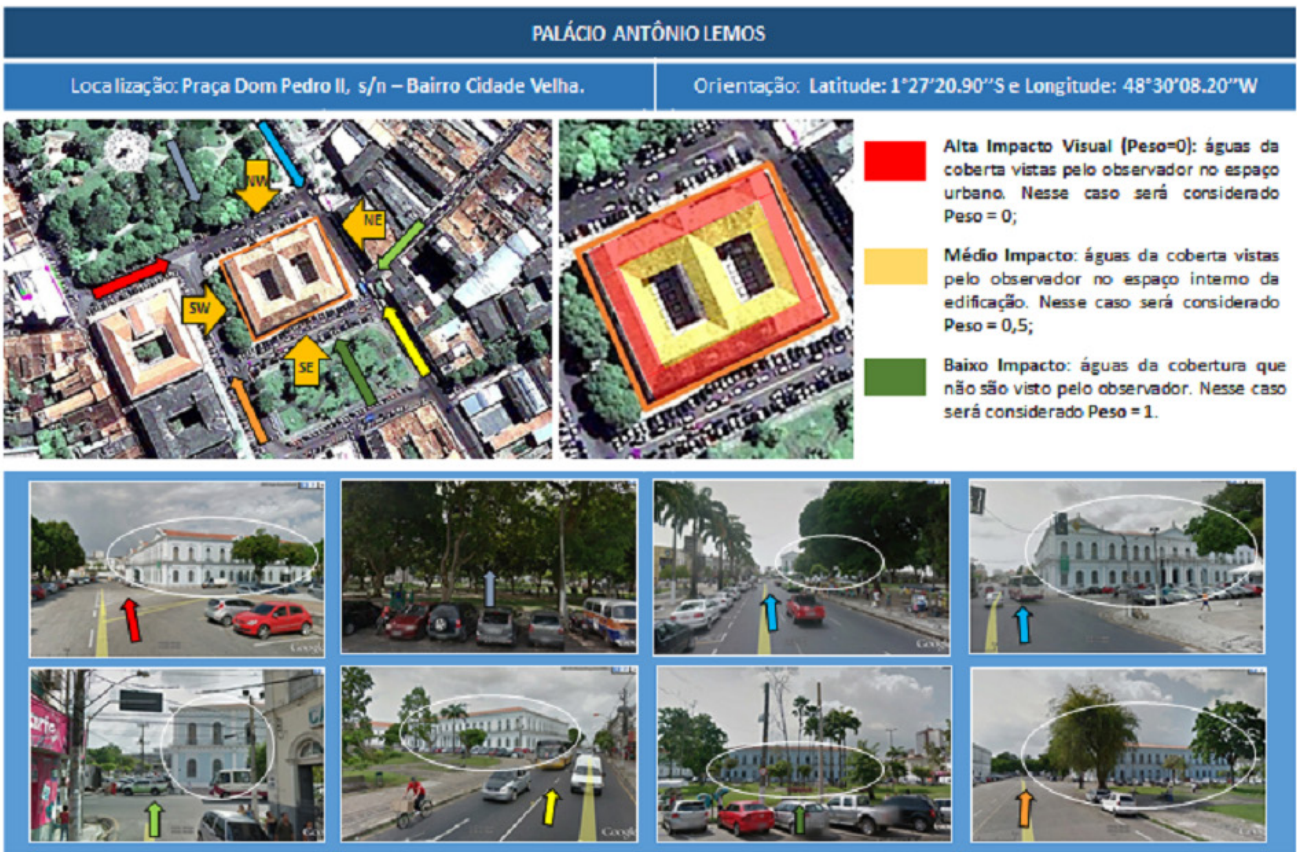

\section{Potencial solar disponível em planos inclinados de telha- do}

Esse passo da metodologia tem como objetivo avaliar o potencial solar disponível em cada face do telhado do edifício, com diferentes ângulos de orientação e de inclinação, e compará-lo a um caso ideal em uma base percentual. As fases desse cálculo serão as avaliações do potencial ideal solar para uma determinada região, com base no azimute e na inclinação dos ângulos, que proporcione as melhores médias, e na avaliação do potencial solar, especificamente na face do teIhado sob avaliação. O resultado desse cálculo, chamado de fator F2, é apresentado na equação (1), em que Href são as horas de sol anuais para a instalação ideal e Hi corresponde às incidências solares anuais verificados na face do telhado.

$$
F 2=\frac{H_{i}}{H_{\text {ref }}}
$$

É importante mencionar que o potencial solar pode ser avaliado a partir de uma base de dados histórica (software, atlas ou estações meteorológicas instaladas longe do prédio) ou ser medido no local de interesse. Para ambos os casos, deve ser observado que a presença de qualquer obstáculo que bloqueia a radiação incidente será considerada e o valor de Hi deverá ser corrigido, considerando o sombreamento.
Figura 5 - Dados necessários para análise do impacto visual da possível integração dos módulos fotovoltaicos, baseado no ponto de vista do observador a partir da rua.

Fonte: Autores, 2014 


\section{Área disponível para a instalação do sistema fotovoltaico e sua relação com as indispensabilidades elétricas da edificação}

Essa etapa visa associar qual a área da face do telhado disponível para a instalação fotovoltaica e a necessidade de eletricidade do edifício. A face do telhado com área suficiente para atender ao consumo de eletricidade vai ter uma maior pontuação nessa etapa. A relação é calculada de acordo com a geração de eletricidade anual média estimada se toda a área do telhado for coberta por módulos fotovoltaicos e o impacto dessa geração na média de consumo anual de eletricidade do edifício. As equações (2) e (3) ilustram o cálculo para determinar o fator F3, o terceiro passo do método proposto.

$$
E_{G}=H_{i} \cdot A \cdot P R \cdot P-A \quad \text { (2) } \quad F 3=\frac{E_{G}}{E_{C}}
$$

A geração fotovoltaica estimada e o consumo de eletricidade do edifício são dadas em $\mathrm{kWh}$; $\mathrm{A}$ é a área de superfície do telhado disponível para a instalação de fotovoltaica, em $\mathrm{m}^{2}$; PR é a proporção estimada do desempenho do sistema, numa base decimal; e o termo P-A é a potência média kWp fotovoltaica instalada por $\mathrm{m}^{2}$ de área de telhado, que dependem basicamente da eficiência da tecnologia fotovoltaica considerada. A tecnologia de célula cristalina apresenta um P-A mais elevado do que a tecnologia de película fina. Valores de eficiência prática da tecnologia monocristalina situam-se na faixa dos $16 \%$, a policristalina, um pouco menor, e a de filme fino, menos ainda. Atualmente estão sendo pesquisadas tecnologias de células multijunção que aproveitem melhor o espectro da radiação, com eficiência da ordem de 40\% [12].

\section{Estudos de casos}

Esta seção apresenta dois estudos de caso com importantes diferenças entre si. O primeiro considera um edifício localizado em Belém, que é utilizado como um processo de referência com o objetivo de apresentar a metodologia em detalhe. O segundo caso trata de estudos desenvolvidos em edifícios históricos reais da cidade de Belém.

\section{Caso hipotético}

O edifício hipotético tem $775 \mathrm{~m}^{2}$ de área total de telhado, distribuídos ao longo das seis faces do telhado com diferentes áreas, azimute e ângulos de inclinação. A Figura 6 ilustra esse edifício. 


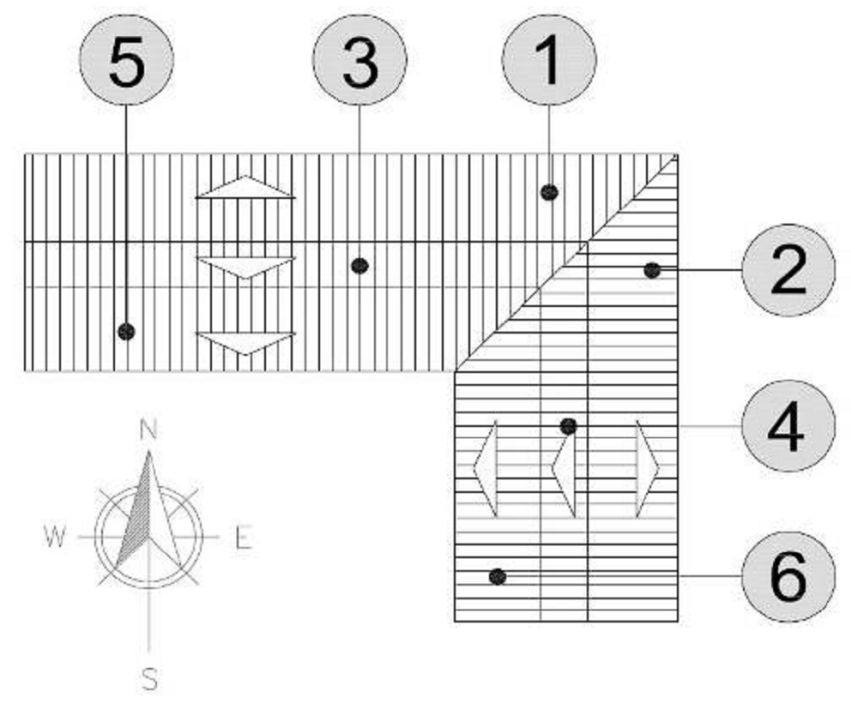

A Tabela 1 apresenta o primeiro grupo de dados de interesse. As horas de sol anuais (Href) para uma instalação ideal em Belém, apresentada na seção 3, e o valor obtido a partir de Meteonorm é de $1.851 \mathrm{~h}$.

\begin{tabular}{|r|r|r|r|l|l|}
\hline Face & Orientação & \multicolumn{1}{l|}{$\left.\gamma^{\circ}\right)$} & $\beta\left(^{\circ}\right)$ & $\begin{array}{l}\text { Área } \\
\left(\mathrm{m}^{2}\right)\end{array}$ & $\begin{array}{l}H_{\text {i }} \\
(\mathrm{h})\end{array}$ \\
\hline 1 & Norte & 180 & 6 & 185,72 & 1,851 \\
\hline 2 & Leste & -90 & 6 & 133,22 & 1,838 \\
\hline 3 & Sul & 0 & 45 & 86,3 & 1,411 \\
\hline 4 & Oeste & 90 & 45 & 58,8 & 1,565 \\
\hline 5 & Sul & 0 & 25 & 137,5 & 1,187 \\
\hline 6 & Oeste & 90 & 25 & 87,5 & 1,399 \\
\hline
\end{tabular}

É importante notar que os valores de Hi para as faces 5 e 6 são influenciados negativamente pela presença de árvores no jardim interno do edifício, como mostrado pela Figura 6, que apresenta também a posição do edifício em relação à rua, importante na análise do impacto visual de cada face do telhado.

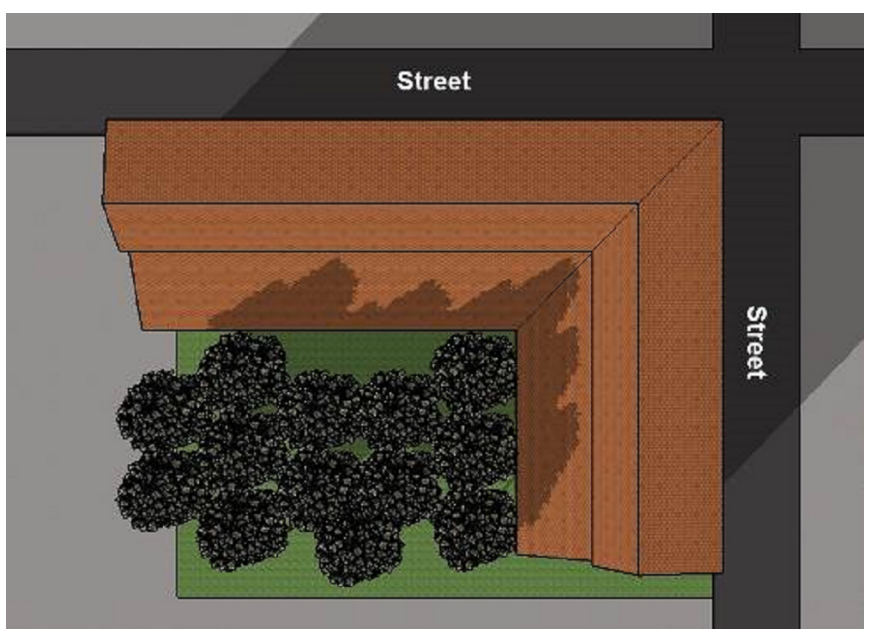

Figura 6 • Identificação e orientação das 6 faces do telhado do edifício hipotético. Fonte: Autores, 2014

Tabela $1 \bullet$ Primeiro grupo de dados da metodologia.

Fonte: Autores, 2014.

Figura $7 \bullet$ Vista do edifício, mostrando a influência do sombreamento em duas faces do telhado.

Fonte: Autores, 2014.

Cadernos de Arquitetura e Urbanismo, v.23, n.33, $2^{0}$ sem. 2016 
O consumo anual de eletricidade do edifício é de $59.000 \mathrm{kWh}$. O impacto visual, o primeiro fator de análise, leva em consideração o impacto causado pelos módulos fotovoltaicos vistos do ponto de vista do observador, como explicado na seção 4.2. Nesse caso hipotético, o observador é alguém que está andando pela rua ou na calçada perto do edifício. O fator F1 é, portanto, alto nas faces 1 e 2 do telhado, sendo visto por qualquer observador na rua; é moderado nas faces 5 e 6 do teIhado, sendo visto apenas por observadores dentro da área do edifício, no jardim; é baixo nas faces 3 e 4 do telhado, sendo visto apenas por uma visão área. A Tabela 2 apresenta o resultado principal da metodologia, com os valores dos três fatores e a pontuação final de cada face do telhado. O resultado final é obtido pela simples soma dos três fatores. Quanto maior a pontuação final, mais adequada é a face do telhado para a instalação fotovoltaica.

Os resultados apresentados na Tabela 2 indicam que a face 1 do telhado é a mais apropriada para a instalação fotovoltaica, seguida pelas faces $4,3,2,6$ e 5 . Os valores do fator F3 indicam que um sistema fotovoltaico cobrindo as três melhores faces é suficiente para atender a todo o consumo de energia elétrica do edifício. Os resultados indicam que, mesmo as faces 3 e 4 tendo um impacto visual baixo, que é o fator mais impactante da análise, a face 1 do telhado é indicada como a mais adequada, pois apresenta azimute e inclinação de ângulos ideais e tem uma grande área de cobertura. As faces 5 e 6 são as menos adequadas devido ao sombreamento, mesmo apresentando um impacto visual moderado.

\begin{tabular}{|c|c|c|c|c|c|}
\hline Face & Eg. P/ ano (kwh) & F1 & F2 & F3 & Resultados \\
\hline 1 & $41.229,84$ & 0,50 & 1,00 & 0,70 & 2,20 \\
\hline 2 & $29.383,00$ & 0,50 & 0,99 & 0,50 & 1,99 \\
\hline 3 & $14.612,32$ & 1,00 & 0,76 & 0,25 & 2,01 \\
\hline 4 & $11.042,64$ & 1,00 & 0,85 & 0,19 & 2,03 \\
\hline 5 & $19.585,50$ & 0,75 & 0,64 & 0,33 & 1,72 \\
\hline 6 & $14.689,50$ & 0,75 & 0,76 & 0,25 & 1,75 \\
\hline
\end{tabular}

\section{Caso "Palácio Antônio Lemos"}

O Palácio Antônio Lemos foi erigido no Século XIX para sediar o poder municipal. Está localizado no bairro da Cidade Velha e é tombado pelas esferas federal, estadual e municipal. Ao longo de sua existência, abrigou o Tribunal de Relação, Junta Comercial, Conselho Municipal e Câmara de Deputados. Atualmente o prédio sedia o Museu de Arte de Belém. A Figura 8 ilustra o edifício do Palácio Antônio Lemos, que tem 19 faces diferentes do telhado com uma área total de cobertura de 3.034 $\mathrm{m}^{2}$. Seu consumo anual de eletricidade é $316.422 \mathrm{kWh}$, Href é igual a 1851, o telhado apresenta baixos ângulos de inclinação, variando entre $20^{\circ}$ e $28^{\circ}$, e inexistem obstáculos sombreando qualquer área da cobertura do edifício.
Tabela 2 • Resultados apresentados sobre sistemas fotovoltaicos.

Fonte: Autores, 2014 


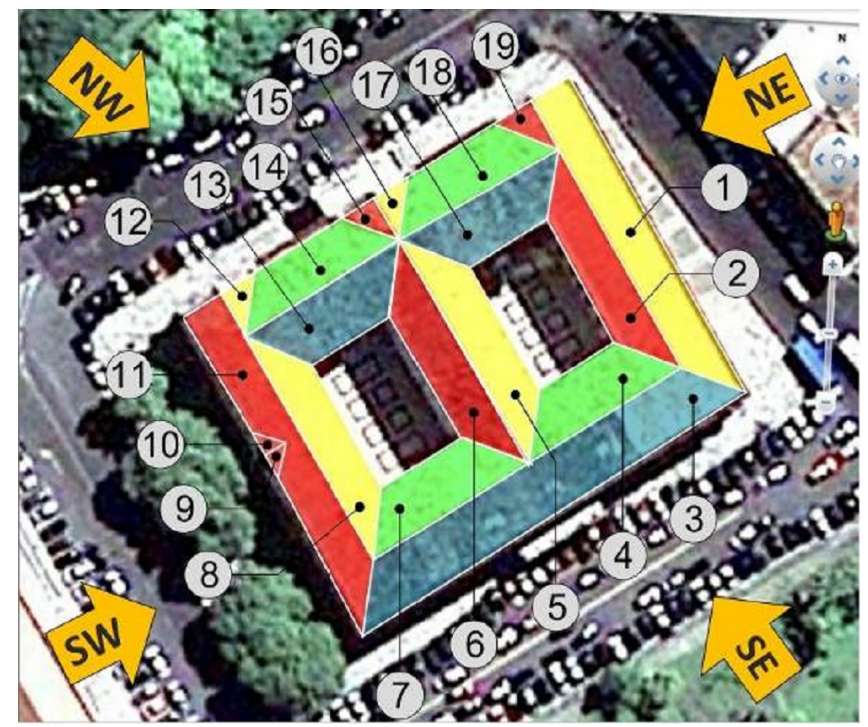

A Tabela 3 indica as faces 4, 7 e 2 do telhado como aquelas com os melhores resultados, com diferenças pouco significativas entre elas, seguidas das faces 6, 17, 13, 8 e 5. Essas oito faces do telhado são suficientes para receber os módulos fotovoltaicos para subsidiar o consumo de eletricidade do edifício inteiro. Aos resultados classificados como insatisfatórios correspondem as faces 12, 16, 15, 19, 9 e 10.

\begin{tabular}{|r|c|c|c|c|c|}
\hline Face & $E_{G: \mathrm{p} / \text { ano }(\mathrm{kWh})}$ & $\mathrm{F} 1$ & $\mathrm{~F} 2$ & $\mathrm{~F} 3$ & Resultados \\
\hline 1 & $59.738,58$ & 0,50 & 0,92 & 0,19 & 1,61 \\
\hline 2 & $45.981,72$ & 0,75 & 0,93 & 0,15 & 1,83 \\
\hline 3 & $87.868,80$ & 0,50 & 0,92 & 0,28 & 1,69 \\
\hline 4 & $40.387,86$ & 0,75 & 0,96 & 0,13 & 1,83 \\
\hline 5 & $39.927,42$ & 0,75 & 0,92 & 0,13 & 1,79 \\
\hline 6 & $40.935,80$ & 0,75 & 0,93 & 0,13 & 1,81 \\
\hline 7 & $40.058,64$ & 0,75 & 0,96 & 0,13 & 1,83 \\
\hline 8 & $41.676,66$ & 0,75 & 0,92 & 0,13 & 1,80 \\
\hline 9 & $1.867,32$ & 0,50 & 0,93 & 0,01 & 1,44 \\
\hline 10 & $1.867,32$ & 0,50 & 0,93 & 0,01 & 1,44 \\
\hline 11 & $59.148,40$ & 0,50 & 0,93 & 0,19 & 1,62 \\
\hline 12 & $7.312,93$ & 0,50 & 0,96 & 0,02 & 1,48 \\
\hline 13 & $30.128,94$ & 0,75 & 0,96 & 0,10 & 1,80 \\
\hline 14 & $38.869,74$ & 0,50 & 0,92 & 0,12 & 1,54 \\
\hline 15 & $7.104,78$ & 0,50 & 0,96 & 0,02 & 1,48 \\
\hline 16 & $7.310,81$ & 0,50 & 0,96 & 0,02 & 1,48 \\
\hline 17 & $30.377,45$ & 0,75 & 0,96 & 0,10 & 1,80 \\
\hline 18 & $39.713,85$ & 0,5 & 0,92 & 0,13 & 1,54 \\
\hline 19 & $7.100,53$ & 0,5 & 0,96 & 0,02 & 1,48 \\
\hline
\end{tabular}

Ao contrário dos resultados obtidos para a construção hipotética, que apresenta um telhado com diferentes ângulos de inclinação e condições de sombreamento, o Palácio Antônio Lemos apresenta um telhado com ângulos de inclinação semelhantes e nenhuma sombra, por essa razão o fator de maior impacto visual é decisivo para a pontuação final. As faces do telhado com melhor classificação têm em comum o fato de
Figura 8 • Identificação e orientação das 19 faces do telhado do edifício Palácio Antônio Lemos.

Fonte: Autores, 2014.

Tabela 3 • Resultados para o Palácio Antônio Lemos.

Fonte: Autores, 2014.

Cadernos de Arquitetura e Urbanismo, v.23, n.33, 20 sem. 2016 
que elas apresentam impacto visual moderado e têm uma boa área de cobertura, condições opostas apresentadas pelas faces do telhado com a pior classificação.

\section{Caso "São José Liberto"}

O edifício São José Liberto possui área total de $2198 \mathrm{~m}^{2}$ de cobertura e tem 32 faces do telhado diferentes para a análise. É uma importante edificação histórica com uso cultural. O prédio principal, data de 1749, foi erguido para ser o convento de São José. Com a expulsão dos jesuítas do Brasil, o prédio abrigou, ao longo de mais de dois séculos de existência, olaria, quartel, depósito de pólvora, hospital, cadeia pública e presídio. Ao final do século passado, o presídio foi desativado e renasceu como Espaço São José Liberto, em 2002, abrigando o Museu de Gemas do Pará, o Polo Joalheiro, Casa do Artesão, o Memorial da Cela, o Jardim da Liberdade, a Capela São José, o Anfiteatro Coliseu das Artes, Espaço Gourmet, seis Lojas de Joias, duas ilhas com serviços especializados em ourivesaria e lapidação, escola de ourivesaria, auditório e mezanino. A Figura 9 mostra a vista superior do edifício, com sua cobertura.

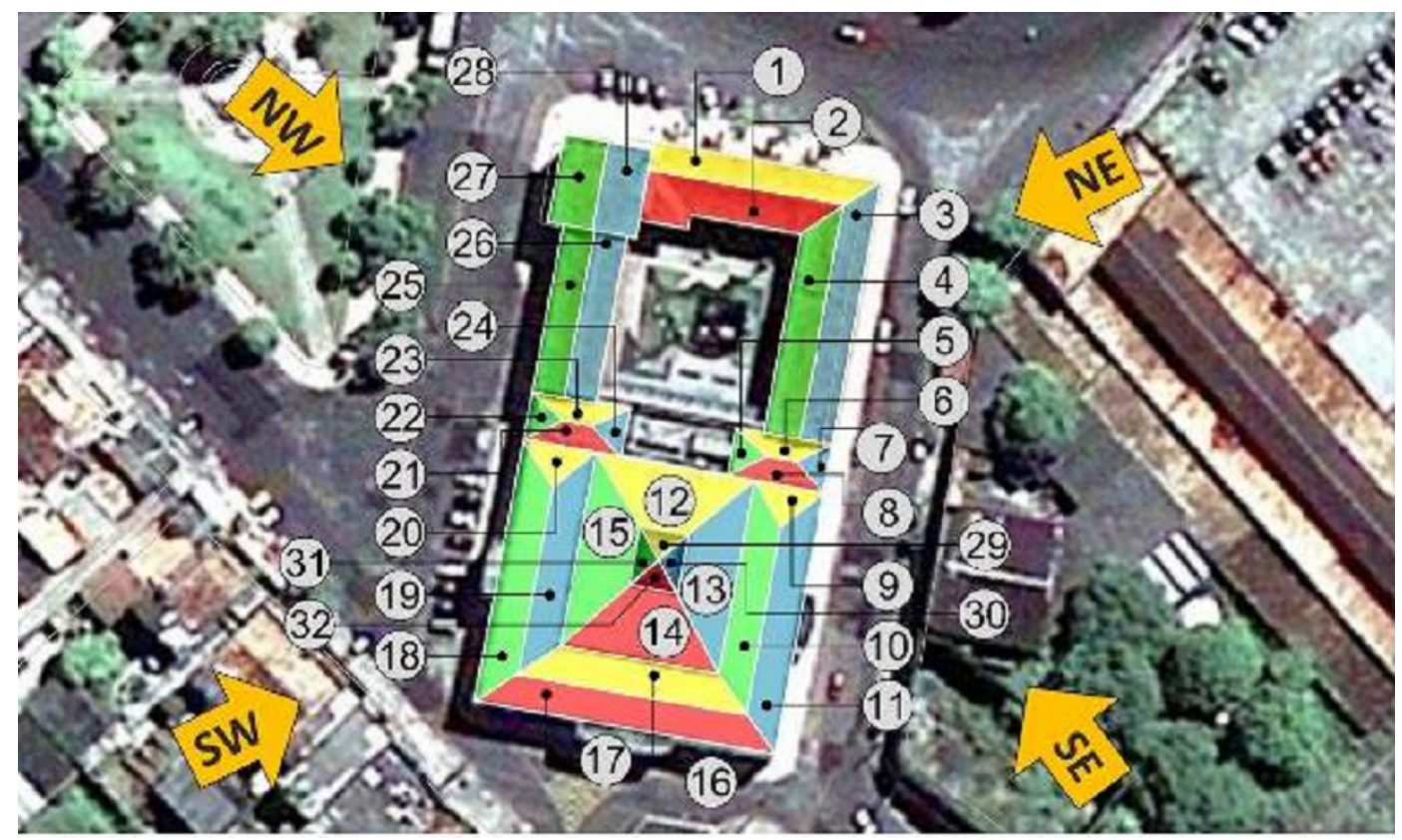

A edificação tem consumo anual de energia elétrica de 894.494 kWh e sua localização geográfica apresenta Href de 1851 h. O telhado apresenta baixos ângulos de inclinação, variando entre 13 e $25^{\circ}$, sem obstáculos de sombra em qualquer área de cobertura do edifício.

A Tabela 4 apresenta os resultados da análise do edifício São José Liberto.
Figura 9 • Identificação e orientação das 32 faces do telhado do edifício São José Liberto.

Fonte: Autores, 2014. 


\begin{tabular}{|c|c|c|c|c|c|}
\hline Face & $E_{\text {c.p/ano(kWh) }}$ & F1 & $\mathrm{F} 2$ & F3 & Resultados \\
\hline 1 & $35.118,22$ & 0,50 & 0,96 & 0,04 & 1,50 \\
\hline 2 & 32,04 & 0,75 & 0,96 & 0,04 & 1,74 \\
\hline 3 & $38.532,95$ & 0,50 & 0,94 & 0,04 & 1,48 \\
\hline 4 & $33.854,61$ & 0,75 & 0,96 & 0,04 & 1,75 \\
\hline 5 & $3.658,05$ & 1,00 & 0,95 & 0,00 & 1,95 \\
\hline 6 & $7.963,11$ & 1,00 & 0,92 & 0,01 & 1,93 \\
\hline 7 & $3.524,92$ & 1,00 & 0,92 & 0,00 & 1,92 \\
\hline 8 & $7.957,63$ & 1,00 & 0,92 & 0,01 & 1,93 \\
\hline 9 & $3.700,18$ & 1,00 & 0,97 & 0,00 & 1,98 \\
\hline 10 & $23.322,75$ & 1,00 & 0,99 & 0,03 & 2,01 \\
\hline 11 & $26.484,16$ & 1,00 & 0,97 & 0,03 & 2,00 \\
\hline 12 & $8.447,00$ & 0,50 & 0,97 & 0,01 & 1,48 \\
\hline 13 & $3.685,05$ & 0,50 & 0,96 & 0,00 & 1,46 \\
\hline 14 & $8.150,00$ & 0,50 & 0,94 & 0,01 & 1,45 \\
\hline 15 & $3.712,15$ & 0,50 & 0,96 & 0,00 & 1,47 \\
\hline 16 & $25.540,76$ & 1,00 & 0,97 & 0,03 & 2,00 \\
\hline 17 & $32.693,76$ & 1,00 & 0,97 & 0,04 & 2,01 \\
\hline 18 & $27.054,22$ & 1,00 & 0,99 & 0,03 & 2,02 \\
\hline 19 & $23.135,86$ & 1,00 & 0,97 & 0,03 & 2,00 \\
\hline 20 & $3.171,28$ & 1,00 & 0,97 & 0,00 & 1,98 \\
\hline 21 & $7.855,87$ & 0,50 & 0,92 & 0,01 & 1,43 \\
\hline 22 & $3.280,43$ & 0,75 & 0,95 & 0,00 & 1,70 \\
\hline 23 & $7.851,24$ & 0,75 & 0,92 & 0,01 & 1,67 \\
\hline 24 & $3.358,13$ & 1,00 & 0,92 & 0,00 & 1,92 \\
\hline 25 & $23.602,32$ & 0,50 & 0,96 & 0,03 & 1,49 \\
\hline 26 & $22.967,28$ & 0,75 & 0,94 & 0,03 & 1,71 \\
\hline 27 & $17.661,60$ & 0,50 & 0,96 & 0,02 & 1,48 \\
\hline 28 & $17.661,60$ & 0,50 & 0,96 & 0,02 & 1,48 \\
\hline 29 & $3.081,12$ & 0,50 & 0,99 & 0,00 & 1,49 \\
\hline 30 & $3.042,48$ & 0,50 & 0,98 & 0,00 & 1,48 \\
\hline 31 & $3.012,24$ & 0,50 & 0,97 & 0,00 & 1,47 \\
\hline 32 & $3.060,96$ & 0,50 & 0,98 & 0,00 & 1,49 \\
\hline
\end{tabular}

A Tabela 4 indica a face 18 do telhado como aquela com os melhores resultados, seguida das faces 10, 17, 11, 16 e 19. A diferença entre elas é muito pequena. As piores classificadas são as faces 31, 15, 13, 28, 14 e 21.

As conclusões apresentadas para o edifício do Palácio Antônio Lemos também podem ser aplicadas a esse caso. A única diferença é o fato de que a construção em estudo tem um maior consumo de energia elétrica, tornando o fator F3 menos significativo para a análise. Se toda a área de cobertura do edifício São José Liberto for coberta com módulos fotovoltaicos, a geração PV atenderá a apenas metade do consumo de energia elétrica do edifício.

\section{Conclusão}

No Brasil, a disseminação de sistemas fotovoltaicos não se encontra no mesmo estágio de outros países, como a Alemanha, a Espanha ou os EUA. Entretanto o público local e agentes privados compreendem a importância de fontes renováveis fotovoltaicas para a matriz elétrica nacional, principalmente nas instalações integradas para edifícios em áreas urbanas desenvolvidas.
Tabela 4 • Resultados do edifício São José Liberto.

Fonte: Autores, 2014 
Embora algumas barreiras necessitem ser superadas para que se alcancem melhores resultados na integração fotovoltaica, especialmente quando aplicada a edifícios já existentes., aA integração arquitetônica correta é uma dessas barreiras, talvez a mais importante para algumas categorias de edifícios, como os edifícios históricos e protegidos. A complexidade dessa discussão necessita de um esforço de pesquisa para permitir a integração fotovoltaica no atendimento a todas ou parte das suas necessidades elétricas. O presente trabalho demonstra que a integração fotovoltaica em edifícios históricos deve ser analisada por arquitetos e engenheiros de uma maneira muito próxima, considerando diferentes fatores, tanto de arquitetura, quanto energéticos.

\section{Agradecimentos}

Os autores deste trabalho gostariam de agradecemr o apoio dos patrocinadores do projeto de P\&D, a Eletrobras-Eletronorte, empresa responsável pela geração e transmissão de eletricidade na região norte do Brasil e ANEEL, Agência Nacional de Energia Elétrica.

\section{Referências}

[1] HAAS, F. Solar energy and conservation of monuments - A contradiction? Proceedings Energy Fórum on Advanced Building Skins, 2013. p. 189-194.

[2] SCOGNAMIGLIO, A.; MUNNO, E. Di; TEMPORIN V.; PALUMBO, M.L. Use of Photovoltaics in historical buildings: an architectural approach, Proceedings 24th European Photovoltaic Solar Energy Conference, 2009. p. 3922-3930.

[3] ANDRADE, C.S.; ROSA, L.P.; SILVA, N.F. da. Generation of electric energy in isolated rural communities in the Amazon Region: a proposal for the autonomy and sustainability of the local populations, Renewable and Sustainable Energy Reviews 15, 2011. p. 493-503.

[4] PEREIRA, E.B.; MARTINS F.R.;ABREU, S.L.; RÜTHER, R. Brazilian Solar Energy Atlas (Original title in Portuguese: Atlas Brasileiro de Energia Solar). São José dos Campos: Inpe, 2006. 60 p.

[5]SUNDATA. Database. Disponível em:<http://www. cresesb.cepel.br/sundata>. Acesso em 25 ago. 2014.

[6]METEONORM. Software. Disponível em:<http://meteonorm.com>. Acesso em 25 ago. 2014.

[7] GALLO, H.; CARRILHO, M.; MAGALHÃES, F. $O$ trabalho de restauro em Arquitetura. In L. Diaféria et al. Um século de luz. [S.I.]: Scipione, 2001. 223 p. 
[8] LYRA, C.C. The matterof use in buildingsof cultural value (Original title in Portuguese: Casa abandonada, ruína anunciada: a questão do uso nas edificações de valor cultural). Technical papers: Working Group IPHAN/BID- Monumenta Program, n. 1, 2000. 23 p.

[9] BELÉM CITY MUNICIPAL COUNCIL. Technical Multipurpose Cadaster of Belém city (Original title in Portuguese: Cadastro Técnico Multifinalitário do Município de Belém), 2000.

[10 IPHAN - Instituto do Patrimônio Histórico e Artístico Nacional. Edital Processo $n^{\circ}$ 01492.000386/2011-99, de 14 de dezembro de 2011. Contratação de serviço de Pessoa Jurídica para Revisão, Complementação e Produção de Material para Subsidiar a Elaboração de Normas de Preservação dos Conjuntos Arquitetônicos, Urbanos e Paisagísticos tombados pelo IPHAN em Belém/Pará.

[11]LYNCH, K.Theimage ofthecity. Series: Harvard-MITJointCenterforUrbanStudiesSeries.TheMITPress; 1stedition, 1960.194p.

[12] BLASQUES, L. C. M. Sistemas de Energia Solar Fotovoltaica Conectados à Rede Elétrica: Conceitos e Aplicações Visando à Sustentabilidade das Edificações, vol. 1. Apostila de curso. Belém: [s.n.], 2015.

Recebido em 01/03/2016

Aprovado em 23/08/2016 
Cadernos de Arquitetura e Urbanismo, v.23, n.33, 2" sem. 2016 